\title{
The Impact of Brand Awareness and Customer Experience on the Brand Loyalty of MI
}

\author{
Yang Zhao ${ }^{1,2}$,Tong Tong ${ }^{1,2}$, Guanchu Li ${ }^{1,2}$, Shuang Ma ${ }^{1,2}$ and Lin Wang ${ }^{1,2}$ \\ ${ }^{1}$ School of Business and Management, North eastern University, Shenyang 110819, China \\ ${ }^{2}$ School of Management, north eastern University at Qinhuangdao, Qinhuangdao 066004, China. \\ Corresponding Email: wanglin05vip@163.com
}

\begin{abstract}
This study discusses the impact of brand awareness and customer experience on brand loyalty of MI. This study randomly selected the people who have purchased the MI's product to complete the questionnaire. The variables of this questionnaire included population statistics variables, the brand awareness of consumers, the experience of consumers when purchasing, and the customer's loyalty of its brand. By using the SPSS to analyze the date from reliability analysis, validity analysis, correlation analysis and descriptive statistical analysis of each variable. As the results shown, brand awareness can positively predict brand loyalty. Service experience and emotional experience can positively affect brand loyalty. There existed significantly positive correlation among brand awareness, service eexperience, emotional eexperience and brand loyalty. Finally, summarizing the empirical results, and bringing up some limitation and expanding direction of this research.
\end{abstract}

\section{Introduction}

With the development of MI, the company has been gaining sorts of loyalty customers. But in the last two years, more competitors began to replicate the marketing strategies of MI, they gained the market share from MI. As to MI, further enhancing customer loyalty became quite noticeable. In this context, considering most users of MI are attracted by its brand profile, and MI's product has huge sales online. So the customer experience seems to be particularly important. This paper made some researches on whether customer experience and brand awareness can promote Customer Loyalty. According to the research of MI's development paths and strategies in recent years, combining the development backgrounds of the current domestic market for smart product, two problems were discussed in this paper. First, what is the relationship between brand awareness of MI and customer experience? Second, how the brand awareness and customer experience influence brand loyalty. Therefore, discussing the relationship among Brand Recognition, Customer Experience and Brand Loyalty is a crucial question which must be faced in today's business. It will be helpful to draw sustainable development strategic policy for MI.

\section{Theoretical review and Hypothesis}

\subsection{Brand recognition}

Due to the high profile of MI, when investigating the cognition of MI's users about brand, using the views of Keller. It is dividing brand awareness into brand profile and brand image. These two dimensions basically cover all the content of brand awareness. Brand profile represents the depth and breadth of brand awareness. Brand image includes the different content of brand awareness [1]. Therefore, when designing the questionnaire, this study investigated from brand profile and brand image.

\subsection{Customer experience}

Up to now, there is no uniform definition of customer experience. Different scholars have different views. By analyzing the previous classification of customer experience, Song Wei combined his study on the characteristic of B2C industry, and divided customer experience into three dimensions: brand, emotion and function [2]. Consumers buy MI's product 
online, it is B2C customer experience. So this research used the view of Song, divided customer experience into functional experience, brand experience and purchase and service experience.

\subsection{Brand loyalty}

After studying the different views of scholars, Yang Yongpan proposed that attitude and behaviour loyalty make up the brand loyalty. Attitude loyalty includes attachment psychology and proposition of attitude. Behaviour loyalty involves buying more and maintaining relation [3]. In conclusion, this study selected attitude and behaviour to design the questionnaire.

\subsection{Research hypothesis}

The way MI's branding is different from the traditional enterprise. The traditional path is to hit brand recognition first. Then build the brand. Finally, increase customer loyalty. But for the Internet enterprise, product is brand. MI's branding focused on loyalty first, marketing itself by word of mouth. After strengthened to some extent, they began to get more brand recognition. It is the initial way of MI. With the high brand profile of MI, most consumers have the awareness of brand, then they decided to buy MI's product. Focusing on whether this way can form brand loyalty, this study raised two issues.

Question one: What is the relationship between brand awareness and customer experience of MI?

Question two: How much impact that MI brand awareness and customer experience of MI caused on brand loyalty? According to the literature review, this paper established a theoretical model preliminarily, as shown in Figure1.

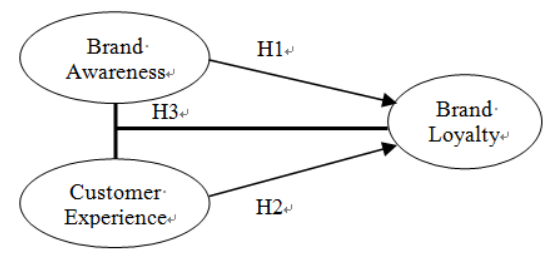

Fig. 1. Prediction of Causal relationship among Four variables.

By the above model, this paper makes the following assumptions, as shown in Table 1:

Table 1. Hypothesis of the Research.

\begin{tabular}{ll}
\hline & \multicolumn{1}{c}{ hypothesis } \\
\hline H1 & Brand awareness can positively predict brand loyalty. \\
H2 & Customer experience has a positive predictive effect on brand loyalty. \\
H3 & Brand awareness, customer experience and brand loyalty are significantly correlated. \\
\hline
\end{tabular}

\section{Research variables}

This study used empirical research method. The questionnaire's design focused on the study of brand awareness, brand loyalty and purchase experience, variables included the population statistics variables, brand awareness of consumer to MI, purchase experience(involving service experience and emotional experience), and consumer's brand loyalty of MI.

Population statistics variables included sex, occupation, level of education, age, personality traits and so on, analyzing whether individual character affects brand awareness, purchasing experience or the degree of brand loyalty. We can know the consumer's brand loyalty of MI through an investigation of MI's profile and brand image in the minds of its users. By investigating consumer's functional experience, service and purchase experience to know the their satisfaction when they are shopping. From two aspects, attitude loyalty and behaviour loyalty, to investigate the brand loyalty.

The Research of Impact of Brand awareness and Purchase experience on the MI's Brand loyalty through specialized online survey platform to answer with multiple-choice questions. Questionnaire holds 23 answer questions and 5 multiple-choice questions, covering a wide range, and its number of questions is moderate. This study began in May 2015 and finished the distribution of questionnaires to users who have bought MI's product. 157 questionnaires were returned, including 11 invalid questionnaires, surplus effective questionnaires were 146. Eventually the survey results were analyzed by SPSS to draw the relevant conclusions, and to prove hypothesis.

\section{Research results}

\subsection{Descriptive analysis}




\subsubsection{Independent sample T test}

In order to confirm the rationality of the 33 questions in the questionnaire, this paper carried out the independent sample $\mathrm{T}$ test. According to the $\mathrm{F}$ value and sig value of A1 A33 can judge the 33 questions have reached a significant level. These date proved that 33 questions can be left to continue studying.

\subsubsection{Reliability analysis}

This study adopts reliability which Cronbach's $\alpha$-coefficient evaluation used, it is generally believed that if the scale $\alpha$ coefficient greater than 0.7 , it is reliable. the sub scale reliability of this research is greater than 0.7 , the overall scale $\alpha$ value is 0.968 , which shows that scale has the ideal reliability.

\subsubsection{Validity analysis}

The difference between the observation values of the scale of validity analysis is used to reflect the real difference of the measured characteristics of things. According to Kaiser's (1974) points, if the KMO value is greater than 0.5, it is suitable for factor analysis. With varimax rotation was used for factor analysis, the analysis results showed KMO value is 0.934 , the significant probability value is $0.000<0.05$, Bartlett test is remarkable. It indicates that is suitable for factor analysis.

The results of factor analysis showed that the characteristics of the 4 principal components are greater than 1 . According Kaiser's guidelines, extract four common factors, after the ingredients are rotated, get the Table 2:

Table 2. Results of Rotated component matrix ${ }^{a}$ Analysis.

\begin{tabular}{ccccc}
\hline \multirow{5}{*}{ Item } & \multicolumn{5}{c}{ Rotational component matrix } \\
\cline { 2 - 4 } & $\mathbf{1}$ & $\mathbf{2}$ & $\mathbf{3}$ & $\mathbf{4}$ \\
\hline A1 & 0.777 & & & \\
A7 & 0.753 & & & \\
A2 & 0.727 & & & \\
A9 & 0.691 & & & \\
A5 & 0.665 & & & \\
A11 & 0.657 & & & \\
A14 & 0.653 & & & \\
A8 & 0.649 & & & \\
A12 & 0.643 & & & \\
A6 & 0.639 & & & \\
A13 & 0.622 & & & \\
A10 & 0.596 & & & \\
A19 & 0.593 & & & \\
\hline A31 & & 0.834 & & \\
A32 & & 0.778 & & \\
A33 & & 0.733 & & \\
A26 & & 0.731 & & \\
A28 & & 0.683 & & \\
A22 & & 0.64 & & \\
A23 & & 0.636 & & \\
A29 & & 0.613 & & \\
A27 & & 0.592 & & \\
A30 & & 0.592 & & \\
A24 & & 0.573 & & \\
A25 & & 0.573 & & \\
\hline A21 & & & 0.71 & \\
A18 & & & 0.694 & \\
A20 & & & 0.638 & \\
A17 & & & 0.638 & \\
A16 & & & 0.619 & \\
\hline A3 & & & & 0.786 \\
A4 & & & & 0.741 \\
A15 & & & & 0.545 \\
\hline & & & & \\
\hline
\end{tabular}

The result of the above table is the composition matrix obtained after sixteen iterations, Items were arranged according to the factors of the load, and the four factors were extracted. Rename these four factors. For the first factor named brand awareness, including item for A1, A2, A5, A6, A7, A8, A9, A10, A11, A12, A13, A14, A19. The second 
factors named service experience, including item for A16, A17, A18, A20, A21. The third factors named brand loyalty, including item for A22, A23, A24, A25, A26, A27, A28, A30, A31, A32, A33. The fourth factor is named emotional experience, including item for A3, A4, A15. Because the factor loading of the variables on each common factor level are more than 0.500 , indicating that the latent variables can reflect the index variables.

The results of factor analysis showed that the scale had good construct validity, and it was suitable for further analysis.

\subsubsection{Correlation analysis}

The following information is the results of correlation analysis between the four variables of brand awareness, service experience, emotional experience and brand loyalty, as shown in Table 3:

Table 3. Results of correlation analysis.

\begin{tabular}{ccccccc}
\hline & mean value & standard deviation & $\mathbf{1}$ & $\mathbf{2}$ & $\mathbf{3}$ & $\mathbf{4}$ \\
\hline 1 brand awareness & 64.0342 & 15.08432 & -- & -- & -- & \\
2 service experience & 21.7945 & 6.09456 & $\mathbf{. 7 3 4 * *}$ & -- & -- & \\
3 emotional experience & 11.863 & 4.01141 & $\mathbf{. 5 4 8 *}$ & $\mathbf{. 5 7 1} * *$ & -- & \\
4 brand loyalty & 48.3356 & 15.54583 & $\mathbf{. 7 3 6 * *}$ & $\mathbf{. 7 1 0 * *}$ & $\mathbf{. 6 0 7 * *}$ & -- \\
\hline
\end{tabular}

From the table we can see that the relevance between brand awareness and other variables, they are all between 0.5 to 0.8 , said the four variables showed a significant correlation, and positive correlation. Hypothesis 3 have been proved. The degree of brand awareness and brand loyalty is the highest which up to 0.736 .

Table 4. Descriptive statistics among variables $(n=146)$.

\begin{tabular}{|c|c|c|c|c|c|c|c|c|c|c|c|c|}
\hline & M & SD & 1 & 2 & 3 & 4 & 5 & 6 & 7 & 8 & 9 & 10 \\
\hline $\begin{array}{c}\text { 1.Brand } \\
\text { awareness }\end{array}$ & 64.0342 & 15.08432 & 1 & & & & & & & & & \\
\hline $\begin{array}{l}\text { 2.Service } \\
\text { experience }\end{array}$ & 21.7945 & 6.09456 & $\begin{array}{c}.734 * \\
*\end{array}$ & 1 & & & & & & & & \\
\hline $\begin{array}{l}\text { 3.Emotional } \\
\text { experience }\end{array}$ & 11.863 & 4.01141 & $\begin{array}{c}.548 * \\
*\end{array}$ & $\begin{array}{c}.571 * \\
*\end{array}$ & 1 & & & & & & & \\
\hline $\begin{array}{l}\text { 4.Brand } \\
\text { loyalty }\end{array}$ & 48.3356 & 15.54583 & $\begin{array}{c}.736^{*} \\
*\end{array}$ & $\begin{array}{c}.710^{*} \\
*\end{array}$ & $\begin{array}{c}.607 * \\
*\end{array}$ & 1 & & & & & & \\
\hline 5.Sex & 1.4 & 0.491 & .050 & .025 & .035 & .024 & 1 & & & & & \\
\hline 6.Age & 2.16 & 0.494 & .144 & $.238^{*}$ & $.199 *$ & $.208 *$ & -.118 & 1 & & & & \\
\hline $\begin{array}{l}\text { 7.Level of } \\
\text { Education }\end{array}$ & 2.86 & 0.563 & -.047 & -.155 & .089 & -.100 & .108 & -.141 & 1 & & & \\
\hline $\begin{array}{l}\text { 8.Monthly } \\
\text { income }\end{array}$ & 1.84 & 1.202 & .101 & .129 & $.169^{*}$ & .102 & -.139 & $.379 * *$ & -.085 & 1 & & \\
\hline $\begin{array}{l}\text { 9. Native } \\
\text { place }\end{array}$ & 1.53 & 0.807 & .080 & .106 & -.020 & -.069 & .112 & -.054 & -.044 & .015 & 1 & \\
\hline $\begin{array}{l}\text { 10.Personalit } \\
\mathrm{y} \text { traits }\end{array}$ & 2 & 0.621 & -.055 & -.020 & -.003 & .001 & 0.000 & -.090 & -.059 & .083 & .014 & 1 \\
\hline
\end{tabular}

\subsection{Empirical analysis}

\subsubsection{Descriptive statistical analysis of each variable}

The average, the standard deviation and correlation of each variable are presented in Table 4 . As can be seen from the table, brand awareness, service experience, emotional experience and brand loyalty are in significantly positive correlation. It can also be seen that population statistics variables and brand loyalty existed in varying degree of negative correlation. Age and service experience are positively correlated, that means the older feels better about Mi service experience of MI. Age and brand loyalty is also significantly positive correlation, the older the consumers are, the stronger their loyalty is. Considering the impact of population statistics variables on the independent variables and dependent variables, the research need to controll population statistics variables in follow-up studies. 
In order to investigate the impact of brand awareness, service experience and emotional experience on brand loyalty, we conducted a hierarchical regression analysis of brand loyalty. Take the population statistics variables as the first-order, brand awareness, service experience, emotional experience as the second-order. According to the views of Aiken and West, when high-order interactions are significant, there is no need to consider whether low-order interactions are significant, as shown in Table 5. Therefore, according to the results of the second stage, we can see that brand awareness, service experience and emotional experience have significant positive predictive effects on brand loyalty. Hypothesis 1 and 2 are verified.

Table 5. Hierarchical regression analysis of brand loyalty.

\begin{tabular}{llcc}
\hline \multirow{2}{*}{ variable } & \multicolumn{2}{c}{ brand loyalty } \\
\cline { 3 - 4 } & Sex & 0.067 & 0.009 \\
& Age & $0.189 *$ & 0.039 \\
\multirow{5}{*}{ First order } & Level of education & -0.08 & -0.058 \\
& Monthly income & 0.033 & -0.033 \\
& Native place & -0.071 & $0.129 *$ \\
& Personality traits & 0.012 & 0.035 \\
\hline \multirow{3}{*}{ Second order } & Second order \\
& Brand awareness & & $\mathbf{0 . 4 1 8 * *}$ \\
& Service experience & & $\mathbf{0 . 2 7 9 * *}$ \\
& Emotional experience & $\mathbf{0 . 2 1 9 * *}$ \\
\hline & $\mathrm{R}^{2}$ & 0.057 & 0.658 \\
& $\mathrm{~F}$ & 1.405 & 29.061 \\
& $\Delta \mathrm{R}^{2}$ & 0.016 & 0.635 \\
\hline
\end{tabular}

According to the actual situation, when the customer's awareness of a brand is 0 , and never experience its products and service, then his loyalty must be 0 . It means the constant is equal to 0 , so this paper selected the standard factor. From the above table, The normalized coefficient of the dependent variable Y (brand loyalty) to the independent variable X1 (brand cognition) is 0.418 , to the independent variable $\mathrm{X} 2$ (service experience) is 0.279 , to the independent variable $\mathrm{X} 3$ (emotional experience) is 0.219 . Therefore, the regression model in this study is established.

$$
\mathrm{Y}=0.418 \mathrm{X} 1+0.279 \mathrm{X} 2+0.219 \mathrm{X} 3
$$

Brabd loyalty $=0.418 *$ Brand awareness $+0.279 *$ Service experience $+0.219 *$ Emotional experience

\section{Discussion and conclusions}

\subsection{Theoretical significance}

This paper adopted the method of Questionnaire to explore the causal relationship among brand awareness, customer experience and brand loyalty. And it brought up three hypothesis. Through an empirical analysis of the survey data, we got four factors, according to the factor analysis changed original three variables into four variables, including the change of the customer experience is divided into the service experience and emotional experience. Because the customer experience included Service experience and emotional experience, it would not affect the hypothesis which is put forward. So in this paper, we draw the following conclusions about the three hypothesis.

The hypothesis that "Brand awareness can positively predict brand loyalty" has been proved in this paper. Through the hierarchical regression analysis, we found that the higher the degree of users' awareness of MI, the more can promote the formation of the brand loyalty. The regression model shows that when the user's awareness of MI degree increased by $10 \%$, the user's Brand Loyalty of MI will be increased by $4.18 \%$. Because the Brand Awareness is a foundation about forming the Brand Loyalty, the more those users know about MI, the more they can feel the value of the brand. So it is necessary to do the positive popularity of Brand Awareness.

The hypothesis that "Service experience and emotional experience can positively affect brand loyalty" has been proved in this paper. The good customer experience can promote the form of brand loyalty. The customer experience includes service experience and emotional experience. When the customer buy a MI's product with service experience and emotional experience respectively increased by $10 \%$, then the customer of MI's brand loyalty will be increased by $2.79 \%$ and $2.79 \%$ respectively. Combined with the actual situation, we can see that if MI pays more attention to customer experience, as its CEO Lei Jun said, the company will do its best to in every contact point to provide best customer experience.

The hypothesis that "Brand awareness, customer experience and brand loyalty are significantly correlated" has been verified. Through the related analysis, we found that the brand awareness, service experience, emotional experience and brand loyalty between these four variables both two have great relevance. The correlation of brand awareness and service experience is 0.734 . The correlation of brand awareness and emotional experience is 0.548 . The correlation of 
brand awareness and brand loyalty is 0.736 . The correlation of service experience and emotional experience is 0.571 . The correlation of service experience and brand loyalty is 0.710 . The correlation of emotional experience and brand loyalty 0.607 .

\subsection{Limitations and future research directions}

This research also has certain limitation, specific description comes as follows:

To begin with, this sample that this study selected cannot be ruled out potential invalid samples' influence on the results of the study, thus, the results of this study are expected to be promoted with further verification. In addition to the sample size, the research ought to select wider dimensions and longer time spanning to cover in the future.

Then, although this study used the method of empirical study and concludes the relationship among brand awareness, customer experience, and brand loyalty, it has not gained accurate analysis of the data, and it also has not variable interactions between specific proportions. Thus, it is necessary to adopt Root Research to further clear the causal relations between the variables in the future.

Finally, the index system of brand loyalty still needs to be further perfected.

\section{Acknowledgements}

This research is supported by funding of China's central university basic scientific research expenses Project No. N152304008.

This research is supported by funding of Northeastern University at Qinhuangdao in China, which Humanities and Social Sciences Key Project No. XNR201601.

\section{References}

1. K.L. Keller., Conceptualizing, measuring and managing customer-based brand equity (Journal of Marketing, 1993)

2. W Song. Research on the impact of B2C e-commerce customer experience on customer loyalty (Jinan: Shan Dong University, 2012)

3. Y.P. Yang, The study on the factors affecting online shopping consumer loyalty (Chengdu: Southwest University of Finance and Economics, 2013) 